NASA Technical Memorandum 102197

(NASA-TM-102197) CONTECLIER EVALUATIONS OP

N $89-25981$

THE DESCENT ADVISOR AUTOMATION AID (NASA.

Anes Research Center) $13 \mathrm{p}$ CSCL 010

$\begin{array}{ll}\text { Unclas } \\ 63 / 03 & 0223921\end{array}$

Controller Evaluations of the Descent Advisor Automation Aid

Leonard Tobias, Uwe Volckers, and Heinz Erzberger

June 1989

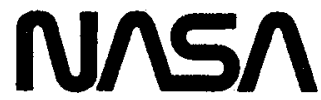

National Aeronautics and

Space Administration 
NASA Technical Memorandum 102197

\section{Controller Evaluations of the Descent Advisor Automation Aid}

Leonard Tobias, Uwe Volckers, and Heinz Erzberger

Ames Research Center, Moffett Field, California

\section{N/SN}

National Aeronautics and

Space Administration 


\title{
Controller Evaluations of the Descent Advisor Automation Aid
}

\author{
Leonard Tobias, ${ }^{\star}$ Uwe Volckers, ${ }^{\dagger}$ and Heinz Erzberger ${ }^{\ddagger}$
}

NASA Ames Research Center

Moffett Field, CA 94035

\begin{abstract}
An automation aid to assist air traffic controllers in efficiently spacing traffic and meeting arrival times at a fix has been developed at NASA Ames Research Center. The automation aid, referred to as the descent advisor (DA), is based on accurate models of aircraft performance and weather conditions. The DA generates suggested clearances, including both top-of-descent point and speed profile data, for one or more aircraft in order to achieve specific time or distance separation objectives. The DA algorithm is interfaced with a mouse-based, menu-driven controller display that allows the air traffic controller to interactively use its accurate predictive capability to resolve conflicts and issue advisories to arrival aircraft. This paper will focus on operational issues concerning the utilization of the DA, specifically, how the DA can be used for prediction, intrail spacing, and metering. In order to evaluate the DA, a real time simulation was conducted using both current and retired controller subjects. Controllers operated in teams of two, as they do in the present environment; issues of training and team interaction will be discussed. Evaluations by controllers indicated considerable enthusiasm for the DA aid, and provided specific recommendations for using the tool effectively. Several additional air traffic control simulations at Ames are planned for 1989 , followed by an evaluation at a major traffic center.
\end{abstract}

\section{Introduction}

Automation in air traffic control (ATC) has been limited to data processing rather than automation of decision-making tasks. The primary reasons for this limitation are the complexity of the decision-making tasks and

\footnotetext{
* Research Scientist. Member AIAA.

† DFVLR, Braunschweig, West Germany, Visiting Scholar at Ames, 1987-88.

$\ddagger$ Research Scientist, Associate Fellow AIAA.

Copyright $(1989$ by the American Institute of Aeronautics and Astronautics, Inc. No copyright is asserted in the United States under Title 17, U.S. Code. The U.S. Government has a royaltyfree license to exercise all rights under the copyright claimed herein for Governmental purposes. All other rights are reserved by the copyright owner.
}

the need to consider the effect of automation on both the airborne and ground systems. There are two distinct paths for investigation of the automation potential for ATC decision systems: total automation or automation aids to assist the controller in specific decision-making tasks. The development of effective automation aids is the subject of this paper. If the controller is to remain in the loop, some significant constraints must be placed on the automation development. It is obvious that controller participation is necessary, not only in initial planning, but on a continuing basis throughout the development and evaluation process. In addition, since the automation tools affect only a portion of the controller task, the automation aid must be integrated effectively with these other tasks. Finahy, as understanding of the situations with which the controtler is confronted grows, it should be possible to extend the applicability of the aid to additional areas in a reasonably straightforward manner. These constraints lead to the following proposed development plan for automation aids.

1) Develop a flexible automation aid to handle a set of decision-making tasks which integrates effectively with existing tasks.

2) Integrate the aid in an operational environment and evaluate the aid in a real-time simulation using controller subjects.

3) Modify the aid to (a) improve its use for the candidate set of tasks and (b) provide assistance in additional situations.

4) Re-evaluate via real time simulation with controller subjects.

5) When the aid is adequately tested in simulation, conduct an evaluation at an ATC facility.

This paper is concerned with a specific automation aid referred to as the Descent Advisor (DA) developed at NASA Ames Research Center. The DA assists arrival sector controllers at an Air Route Traffic Control Center (ARTCC) by providing advisories and suggested clearances to achieve desired time or distance spacing. The concern here is not with a detailed description of the 
automation aid itself, which can be found in Ref, 1, but rather with step 2 of the development plan described above, the initial controller evaluation process. A realtime simulation was conducted of selected sectors at the Denver ARTCC. First, a summary of present day operations at Denver is presented, followed by a description of the Ames ATC simulation facility. Finally, the controller evaluations are described. The simulation also included an airline quality simulator flown by airline crews. Aircraft performance and pilot related issues are discussed in a companion report. ${ }^{2}$

\section{Arrival Traffic At Denver}

One of the difficulties in developing automation tools is the lack of documentation describing operational procedures. The ATC Handbook (Federal Aviation Administration, Air Traffic Control, 1110.65B, 1988) provides various constraints, such as distance separations or runway separations for independent operations. It also specifies controller phraseology for issuing clearances. In addition to the handbook, documentation is available on route structure, sector boundaries, and other restrictions. However, information on the dynamics of operation, i.e., how to control multiple aircraft efficiently within the bounds specified, must be learned by discussion with controllers and by direct observation. Since it would be very time consuming to develop an understanding of operational procedures for each Center, it was decided to focus the initial development on the Denver ARTCC.

There are many reasons for choosing the Denver ARTCC for an initial evaluation of the DA. Denver is one of the few Centers that has had significant experience with time-based operations. Since the DA is a potential aid for both distance spacing and time-based operations, it would be advantageous to evaluate it in an ARTCC where controllers were familiar with both types of operations. Also the effectiveness of the DA in planning depends on the quality of wind information. Because of ongoing research at $\mathrm{NOAA}^{3}$ there is more frequently updated wind data available than at other Center locations. In addition, Denver's operations, while not the most complex, have certain complex features-Denver is a major hub and has significant weather problems-which make it a worthwhile first choice for study.

The following section highlights the current operational procedures for handling arrival traffic at the Denver ARTCC. Denver has four main arrival directions. There are multiple arrival routes for each of these directions, but all arrivals are merged into four streams, and are thus handed off to the Terminal Radar Approach Control (TRACON) at one of four metering fixes: Drako, Keann,
Kiowa, and Byson, representing traffic from the Northwest, Northeast, Southeast, and Southwest, respectively. A map depicting the main high altitude arrival routes and the Denver Center boundary is given in Fig. 1. This airspace, including both high and low altitude airspace, is divided into 35 sectors. It is interesting to note that separate groups of controllers handle each of the four arrival directions. Because of this and because of differences in sector geometry and underlying terrain, arrival procedures differ somewhat depending on arrival direction.

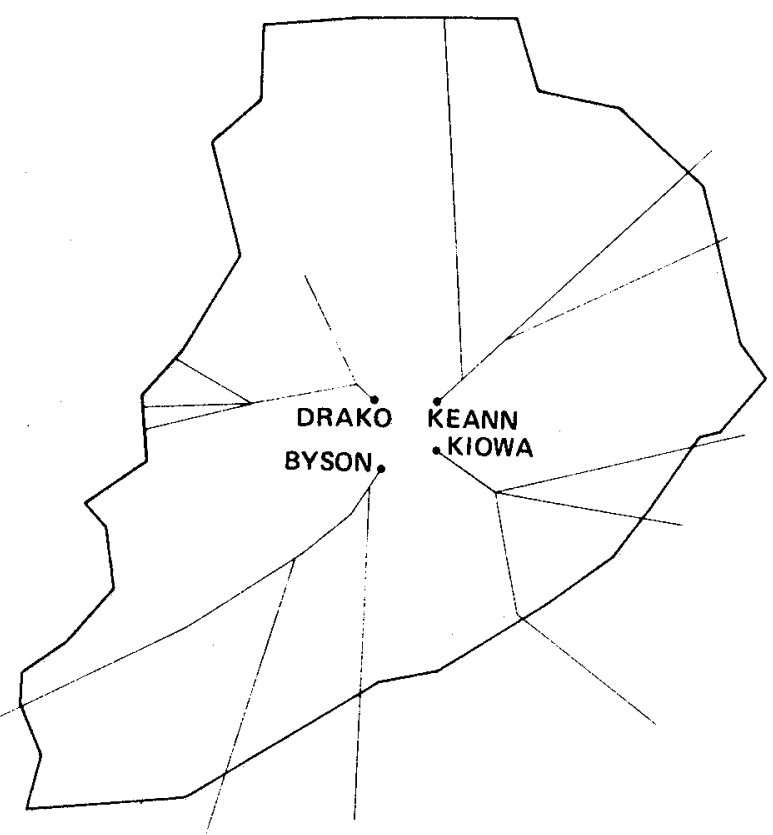

Fig. 1 Denver arrival routes.

Denver's Stapleton International Airport is a hub for two major carriers, United and Continental. Thus, typically there are busy arrival traffic periods, which are followed about $\mathbf{4 0} \mathrm{min}$ later by a departure rush. Typically, an arrival rush from the West occurs when arrivals from the East are light, and vice versa.

For each arrival direction, the approach is handled by a high altitude sector followed by a low altitude sector. Each sector is staffed by one or two controllers depending on traffic load, and the high and low sectors are typically adjacent. The physical proximity of the sector positions within the control room permits the high altitude controller to glance at the low altitude sector display and 
adjust his clearances accordingly. However, there are some exceptions worth noting. Because of high communication loads, the Southwest arrivals are handled by two high altitude sectors prior to reaching the low sector. Also, for the Northeast arrivals, high and low sector positions are not adjacent because the high sector must be kept near a different sector for departure operations. Northeast high and low arrival coordination is thus achieved by voice only.

Traffic entering Denver airspace consists of about $60 \%$ arrivals and $40 \%$ overflights. However, while many high altitude arrival sectors have to adjust flight paths for overflights, the Northeast high altitude arrival sector is generally free of overflight traffic.

Sector operations at the Center currently operate according to one of two goals. For light to moderate traffic, the goal is to establish a prescribed intrail spacing of aircraft over each metering fix. Under heavy traffic, metering is in effect. In this case, the low altitude controller attempts to provide aircraft over the metering fix at a set of specified times. In either metering or intrail spacing, the clearances which need to be generated to achieve the goals are entirely the controller's responsibility.

To illustrate operational procedures, consider the high altitude arrival routes from the Northwest leading to the metering fix Drako as shown in Fig. 2. The high altitude sector (FL 240 and above) is sector 14, and the underlying low altitude sector (FL 230 and below) is sector 13 .

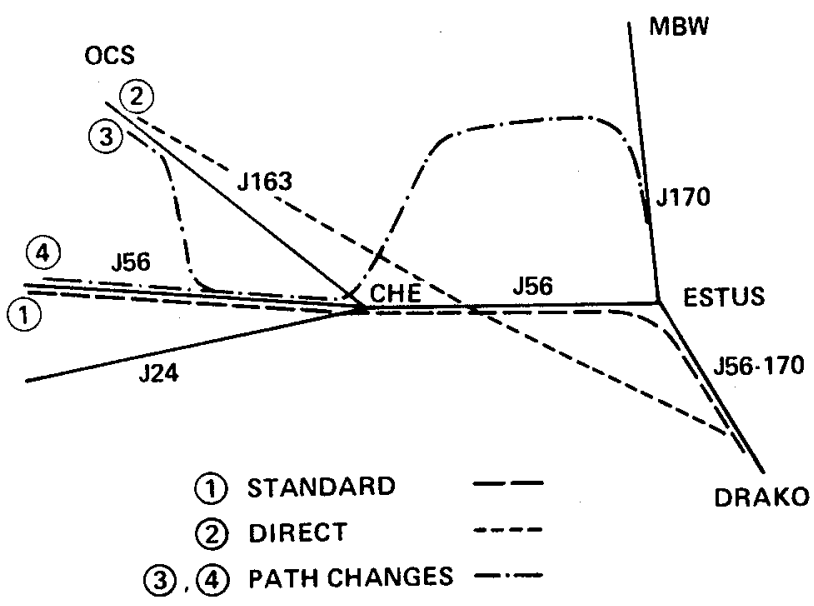

Fig. 2 Northwest arrival routes.
Traffic from the West enters sector 14 after crossing the Salt Lake-Denver ARTCC boundary along the jet routes J163, J56, and J24. Additional traffic (not shown) arrives from the North (from Medicine Bow) from sector 34. The figure also shows a standard flight path from the Center boundary to the metering fix. This might be the standard track observed under moderate traffic conditions, when the goal might be to provide traffic over the metering fix $7-8 \mathrm{n} . \mathrm{mi}$. apart. If traffic is light, the controller might provide a more direct routing to Drako, while under heavy traffic conditions, various vectoring strategies may be used to effect path changes, depending on the wind condition, sector boundaries, location of other traffic, the amount of delay required, and individual controller technique. During periods of very heavy traffic, selected aircraft arriving along $\mathrm{J} 170$ may be rerouted to the Northeast arrival, a procedure known as gate balancing.

During the summer months, thunderstorms complicate operational procedures. Typically, Stapleton is affected by thunderstorms an average of 60 days/year. Thunderstorms develop over the Rockies to the west of Stapleton Airport and move generally eastward across the plains. Since neither the speed of the disturbance nor its direction is predictable with great accuracy, it is often necessary to close certain arrival routes affected by thunderstorm activities and to change runway landing directions. Sectors which are free of thunderstorm activity often experience heavy traffic, which may include a mix of arrivals and departures rather than the normal arrival traffic only. Individual sectors experiencing heavy traffic are often staffed by three controllers, rather than the usual one or two. One controller operates the trackball and keyboard, while the second handles communication with all aircraft within the sector. The third handles the flight strips.

It should be clear from this discussion that an inflexible automation aid, i.e., one which requires strict adherence to a specified route structure or strict compliance under all situations, is one which controllers will find unacceptable. Controller operations not only vary from center to center, but also from sector to sector and even from controller to controller. It should not be surprising that the multi-aircraft control problem has a multitude of acceptable solutions. An effective automation aid must allow for these differences and support them appropriately.

\section{Simulation Facility}

The ATC Automation Laboratory at NASA Ames Research Center is a unique national facility for 


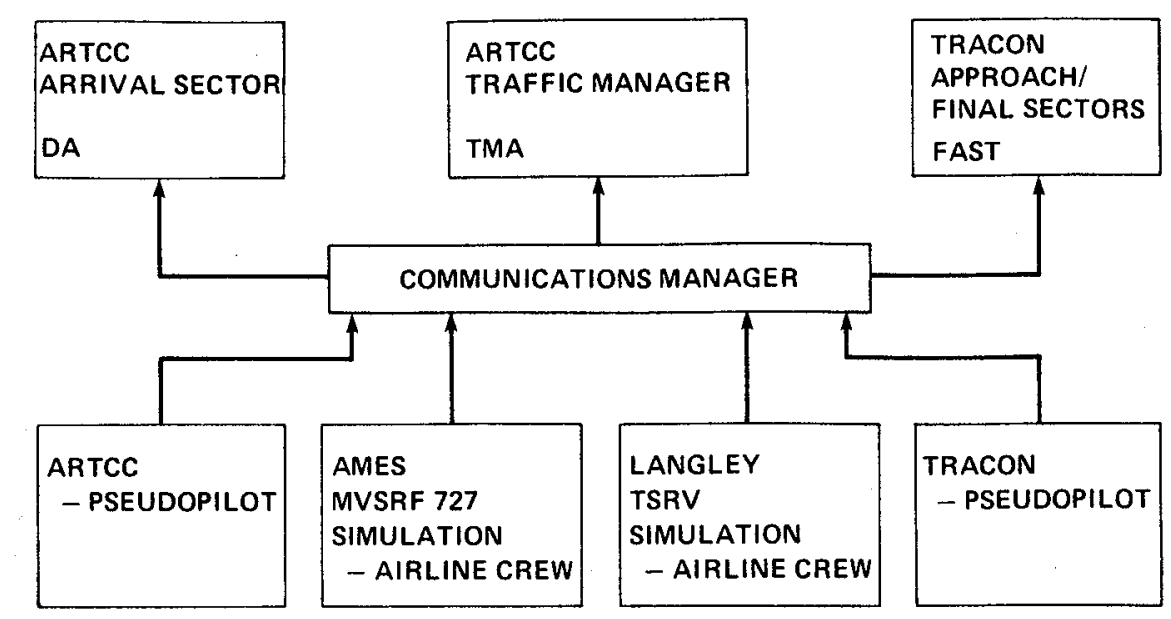

Fig. 3 Ames ATC automation laboratory.

developing and evaluating automation aids. A block diagram of the laboratory is shown in Fig. 3. The top half of the figure represents the ground-based elements of the simulation. Automation aids are under development for the Center traffic manager, the Center arrival sector controller, and the TRACON controllers; they are denoted the Traffic Management Advisor (TMA), the DA, and the Final Approach Spacing Tool (FAST) respectively. The TMA and FAST, like the DA described earlier, should be considered a toolbox for the controller rather than a tool having one specific function. The primary function of the TMA is to plan the most efficient landing order and to assign optimally spaced landing times to all arrivals. In addition, the TMA assists the traffic manager in efficiently rerouting and rescheduling traffic in response to major disruptions such as runway reconfiguration or weather disturbances. FAST provides the final controller with a set of tools for speed adjustment and for initiating turns to achieve desired spacing on final approach. Both TMA and FAST are under active development.

Each position can be operated by one or two controllers, depending on traffic load and test condition. At present, flight strip information is not displayed electronically so a flight strip rack is provided adjacent to the Center sector display, and is managed in the usual way by the data controller.

The bottom half of Fig. 3 represents the airborne elements of the simulation, consisting of pseudopilot stations and communications links to piloted simulators.
Each pseudopilot station can control up to 20 pseudoaircraft, depending on the activity of the specific sector. A typical pseudopilot display is shown in Fig. 4. The upper left portion of the screen provides the pseudopilot with a list of all aircraft under his or her jurisdiction together with the heading, altitude, ground speed, and expected time of arrival at the metering fix. In addition, the last five clearances which were executed are tabulated. The upper right portion is a map display showing all traffic being controlled. In the lower left is the clearance entry area, which has the command glossary summarized at the bottom. Note that the clearance vocabulary includes vectoring clearances, speed, and altitude or any combination thereof. In addition, clearances generated by the DA consisting of a distance measuring equipment (DME) point for top of descent and a speed profile can be entered. A handoff clearance is used to transfer an aircraft from the Center to TRACON. Finally, time-based clearances can be issued to 4D equipped aircraft. There is a choice of input devices, mouse, function keys, or keyboard, but function keys have been the most effective. For commands involving waypoints (capture, hold, intersect) and for aircraft identification, pull-down menus are provided. The lower right corner of the display provides simulation status information including the current sector being simulated.

The ATC Simulation includes performance models for the pseudo-aircraft which are used to compute changes in aircraft trajectory for each pseudopilot input. Initially, each pseudo-aircraft trajectory is based on initial 


\section{ORIGINAL PAGE IS \\ OF POOR QUALITY}

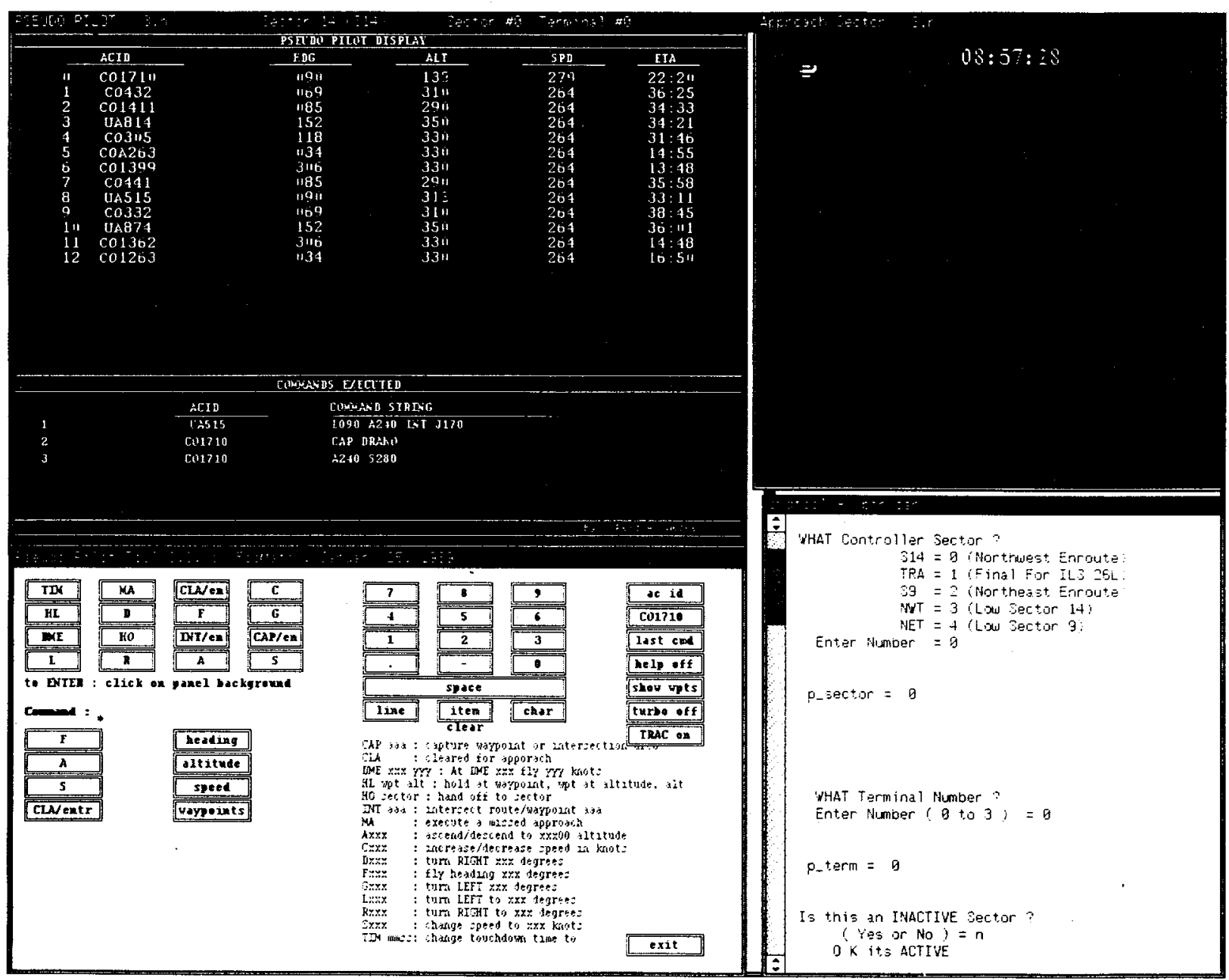

Fig. 4 Typical pseudopilot display.

conditions at the center boundary crossing. Different entry points were assigned to each aircraft participating in the simulation with a specific entry altitude assigned to each route. For the initial evaluation, entry speeds and altitudes were set at a constant value according to the assigned arrival route.

In addition to pseudo-aircraft, the ATC Automation Laboratory is linked to two piloted simulators, the Man Vehicle Systems Research Facility (MVSRF) 727-200 simulator located at Ames about one mile away from the Automation Lab and the Transport Systems Research Vehicle (TSRV) 737 simulator located at NASA Langley Research Center in Hampton, VA. The MVSRF 727 cockpit simulator is a six degree-of-freedom, moving base simulator. Its aircraft dynamics and local environment are controlled by a SEL 3277 digital computer which, in turn, is linked to the ATC Lab by a serial data link. The pilots "flying" this simulator are in voice communication with the Approach Controller. Local environmental conditions for this aircraft are simulated by the SEL computer; these conditions are coordinated with those used for the pseudoaircraft performance. The TSRV simulator is a fixed-base replica of the research flight deck of the TSRV aircraft. The simulator includes a model of a Boeing 737-100 aircraft including landing gear dynamics, gust and wind models, radio navigation system models, and instrument and microwave landing system models. A description of this simulator can be found in Ref. 4. 


\section{Operational Procedures for Using the DA Automation Aid}

Traffic control of arrivals in the center environment involves predicting and controlling spatial or time relationships of multiple aircraft at the metering fixes, the handoff point to the TRACON. Using current manual procedures, controllers generally visualize traffic situations about 5-10 min into the future, at which time they would issue clearances to achieve the desired space/time relationship. By using the Descent Advisor (DA) automation aid, controllers can begin to resolve situations about $25 \mathrm{~min}$ in advance. With this additional lead time, speed control, rather than vectoring, can resolve many situations. In addition, earlier studies (Ref. 5) have shown that, using DA-generated clearances, pilots could achieve accuracy of $\pm 20 \mathrm{sec}$ at the metering fix. Strictly manual procedures generally result in time accuracies of $\pm 1 \mathrm{~min}$ at best. This section will describe what information is provided to controllers and how to use this information to control sector arrivals.

Toolbox-generated information is provided in three distinct screen locations on the controller display: the DA menu, the timeline and the map. A typical controller display depicting high altitude arrival traffic to the Drako metering fix is shown in Fig. 5. The menu at the top of the screen provides the specific clearances as generated by the DA. The sample menu data is reproduced in Table 1. The top line of the menu indicates that $\mathrm{CO} 414$ will follow the standard procedure (SP) and will land at 9 min past the hour. For UA77, the controller has taken action to delay the arrival time from the SP and requested an alternate speed profile DA. The advisory consists of a TOD point (58 DME) and the Mach number/indicated airspeed $(0.70 / 230)$.

\section{Table 1 Typical Menu Data}

$\begin{array}{lllll}13: 09 & \text { SP } & \text { CO } 414 & 64 & 0.72 / 280 \\ 13: 13 & \text { DA } & \text { UA 77 } & 58 & 0.70 / 230\end{array}$

The second source of DA generated information is the time line. The time line, shown on the left in Fig. 5, provides graphically the future time relationships of aircraft at a designated time control waypoint. In the figure, the Drako metering fix at the Denver Center has been selected as that point. The scale covers a time range of about $30 \mathrm{~min}$, with future time increasing toward the top in 1-min increments. The current Zulu time (or Greenwich Mean Time) is shown just below the time line. During operation the controller observes the time-line scale moving steadily toward the bottom of the display. At

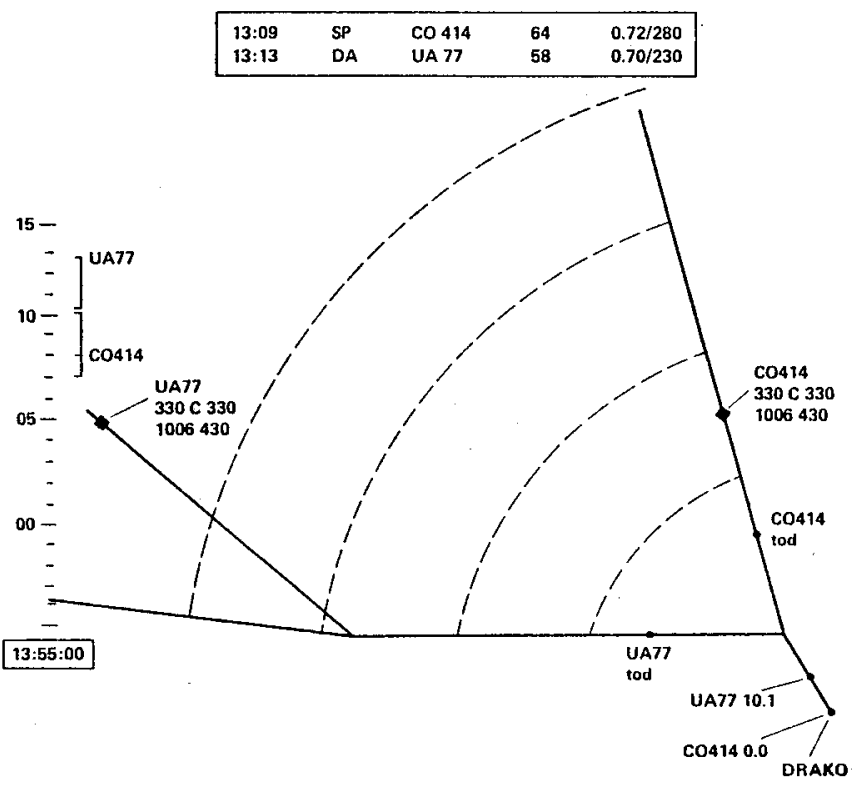

Fig. 5 Arrival sector display with automation tool.

the point where the downward sliding scale runs into the margin line, future time becomes current time.

The use of a time line as a controller tool has been under investigation for many years. An early study (Ref. 6) looked at using time lines to develop time assignments at multiple time control points. An AI-based approach for traffic planning using time lines is discussed in Ref. 7. Time lines play a key role in the planning system COMPAS (Ref. 8) which was developed at the DFVLR in Germany and is currently being implemented at Frankfurt.

For each aircraft, the time line indicates two times. The time to the left of the line represents a scheduled time, while the time on the right is a predicted time. The scheduled time could be that received from the TMA or it could represent a time plan generated by the sector controller. The time on the right is the predicted time at the metering fix. It is either DA-generated or, if no advisory is generated, based on standard airline procedure. In the figure, a time range bar is provided for UA77. The time range enclosed by the brackets indicates the maximum variation of arrival time achievable through speed profile management along a fixed arrival route.

Finally, additional toolbox-derived information appears on the map itself. The map information provided 
by the DA in Fig. 5 includes the top-of-descent (TOD) marker, route-intercept point, and distance spacing data. Each category of information is color coded, and, in order to reduce clutter, is shown only for those aircraft requested by the controller. The TOD corresponds to the information provided on the menu. In addition, for aircraft which are currently flying outside a standard route corridor but which are heading towards a standard route, the intercept point is shown. The distance spacing tool looks ahead to when one of the aircraft is at the metering fix and estimates the location of the other aircraft at that time. In the figure, UA77 is predicted to be $10 \mathrm{n} . \mathrm{mi}$. behind CO414 is at Drako. This prediction is based on the DA as generated for each aircraft, or by one of two calculations known as SEP1 or SEP2. For either calculation, a desired intrail spacing distance is assumed. For SEP1, the spacing distance is to be achieved by altering the DA of the following aircraft within its time range while keeping the current plan for the lead aircraft. In SEP2, the current plan for both aircraft can be altered. The above constitutes a brief summary of what information is available; more detailed information together with a description of the interface is given in Ref. 1.

The information on the menu, time line, and map can be used in a variety of ways, depending on traffic situation and each individual controller's traffic handling techniques. For the May 1988 simulation, a moderate traffic load was simulated, and it was stipulated that a 10-n.mi. intrail spacing requirement was in effect at the metering fix. For this situation, the automation tools could provide a longer planning horizon, thereby avoiding intense vectoring in the vicinity of the metering fix and avoiding the need to develop a long, single stream of aircraft at the same speed and altitude. Consider an arrival aircraft just handed off from the adjacent Center. A typical collection of aids would be as follows. To assist the controller in focusing on specific aircraft, a highlight feature is used which changes the color of information displayed from the standard green to yellow. The controller could examine the time line to determine where in his existing planned sequence the new arrival would fit. He could examine the aircraft's preferred profile, or use the time range bar to examine altemative sequence positions. Once a tentative sequence plan was established, he could use SEP1 or SEP2 to determine if the desired intrail spacing was achievable without altering planned arrival routes. If it was achievable, he could issue the DA clearance available in the menu at that time or perhaps observe the map display and issue the clearance as the aircraft neared the TOD. If he determined that the aircraft needed to be vectored off the route, he could use the route intercept information to determine where the aircraft would intercept a desired route, and could still get a specific descent clearance for this aircraft. The operative word in the above is "could." He could chose not to use a specific tool, depending on his own technique, or perhaps depending on some specifics of the situation which may be unknown to the automation aid.

\section{May 1988 Simulation Evaluation}

In the near future, a formal real-time simulation evaluation of the DA is planned in which traffic scenarios will be simulated starting just prior to a busy period and then continuing until after the busy period is over. Denver Center controllers will control traffic in a baseline mode which represents the simulation approximation to present day operations and in a DA-assisted mode. Operations will be compared based on controller evaluations and qualitative criteria such as separation at metering fix, average number of clearances per aircraft, and average delay per aircraft. The May 1988 evaluation was the first of two evaluations (the second was conducted in March 1989) leading to the type of evaluation just described. Its purpose is to identify problem areas with the simulation facility and with the automation aids at an early stage of development. The issues addressed here should be of considerable interest to those involved in the Advanced Automation system (AAS) implementation and to any organization developing automation aids involving extensive controller testing. (The later study, conducted in March 1989, utilized controller subjects who were active controllers at the Denver ARTCC, and who controlled traffic in the arrival sectors simulated. A report describing this evaluation is in preparation.)

The subjects consisted of five teams of two controllers each. None of the subjects were familiar with the Denver Center. Two teams had been exposed to an earlier version of the Descent Advisor, and two teams consisted of presently active Oakland Center controllers. The active controllers had never been exposed to the DA prior to the present trial. Controller experience ranged between five and twenty years.

Each team spent two days at Ames, the first for training, the second for evaluation. The training day began with a 15-min orientation in a briefing room to introduce the DA and to outline the pilot and pseudopilot interfaces. The subjects would then be brought into the lab for handson training directed by two instructors. The instructors themselves were former controllers who had spent the previous week learning to operate the system.

The sector approach controllers normally work as two-man teams, one person monitoring the radar traffic as displayed by the CRT (the radar controller) and the other 
controller entering information onto the flight strips and operating the keyboard (the data controller). In using the DA, the controller who normally operates the keyboard would then operate the mouse since the keyboard is replaced by the mouse as the input device.

During the training day, each team member would complete two runs at each position, one with and one without the DA. A run is a 90 -min simulation period during which a low to moderate traffic flow was generated. Thus, each team would complete a total of four training runs prior to the start of the experimental runs on the second day.
At the end of his evaluation period, each controller completed a questionnaire which took roughly one hour to complete. For example, the controller was provided with a statement such as: "It was difficult to select menus or data by using the mouse." He was asked to rate each statement on a scale from " 1 " to " 6 ", where " 1 " indicates "strongly agree" and " 6 " indicates "strongly disagree." He was encouraged to provide comments or explanations for any responses. There were 30 questions using this format followed by 5 summary questions such as: "In what situations was the DA display not helpful?" A set of questions and responses relating the effectiveness of the DA is shown in Fig. 6 and is described below.
STATEMENT

THE DA PROVIDES REASONABLE INFORMATION UPON WHICH ONE CAN RELY.

WITH THE DA ONE HAS A BETTER AND EARLIER IDEA ABOUT FUTURE CONFLICTS/SEPARATION OVER THE METERING FIX.

ADDITIONAL VECTORING OR SPEED CONTROL WAS NOT NECESSARY.

IT WAS EASY TO COMBINE THE DA-GENERATED ADVISORIES AND MY OWN VECTORING OR SPEED COMMANDS.

THE DA RESTRICTS MY PERSONAL FREEDOM AND MY OWN DECISIONMAKING.
CONTROLLER RESPONSE
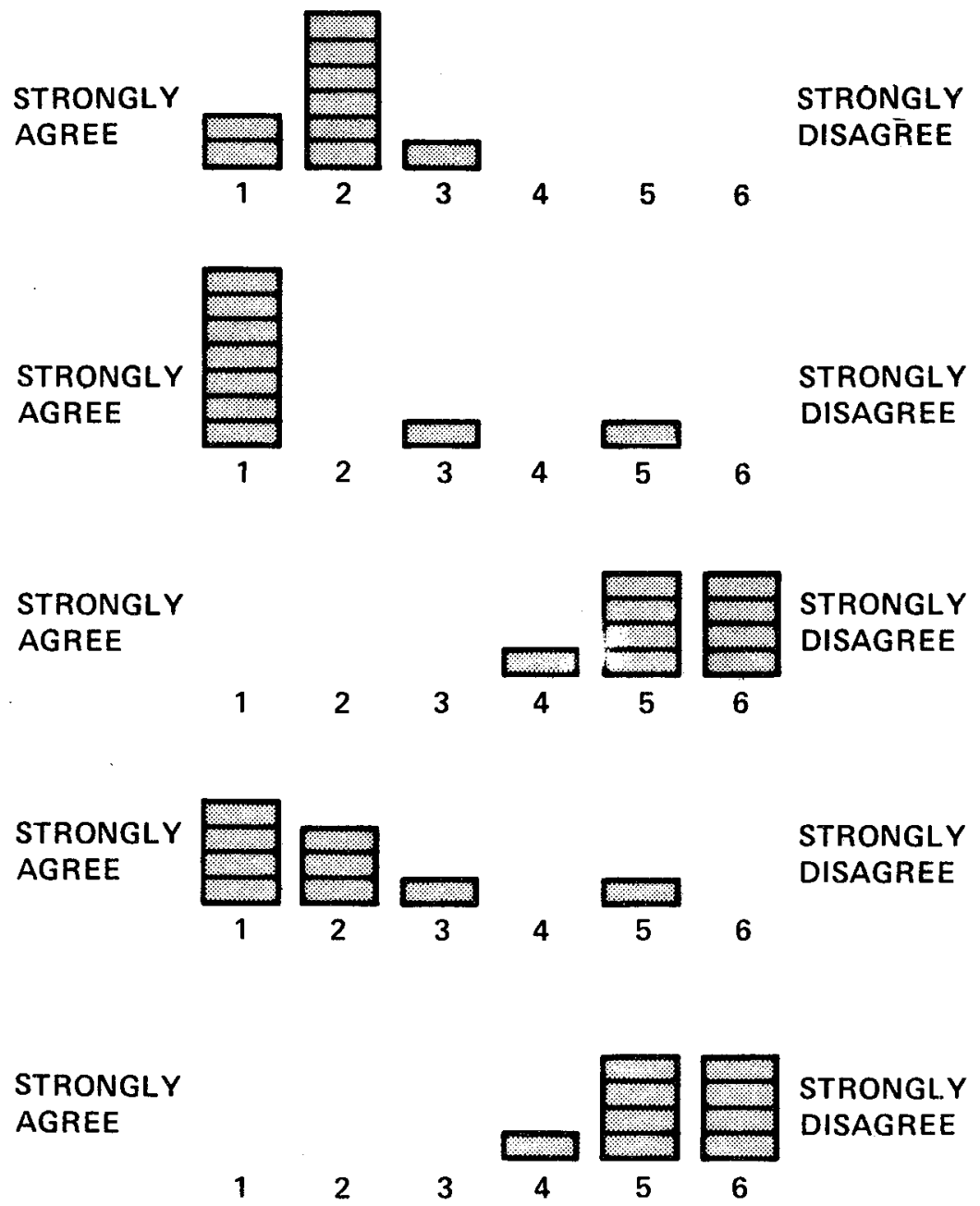

Fig. 6 Controller evaluation of the DA: May 1988. 
The discussion which follows summarizes the controller questionnaire responses in terms of four general areas: the effectiveness of the automation tool, controller training, simulation realism and use of the interactive graphics display. In the ensuing discussion, controllers responses are considered as a consensus if seven of the nine subjects "strongly agree" (by checking 1 or 2 ) or "strongly disagree" (by checking 5 or 6). It should be noted that many of the specific issues raised have resulted in software modifications which are described in Ref. 1 and which are being evaluated in new simulation tests.

\section{Effectiveness of the DA Automation Tool}

A major guideline in the development of the DA automation aid is to provide a flexible aid which can be used in a variety of ways according to the specific needs of individual controllers. The controllers indicated in the evaluation that the DA did not restrict their personal freedom and their own decision-making. Controllers could use the DA whether or not the aircraft was on a standard route. If it wasn't on a standard route, they could use it in a route intercept mode or a waypoint capture mode. Controllers could ignore clearances generated by the DA for a period of time and then resume its use. The assessment of the information the DA provides was very favorable. Controllers indicated that the information is reliable and that it provides a better and earlier idea concerning future conflicts and separation at the metering fix. The controllers agreed, as expected, that the additional vectoring was still necessary; i.e., conditions existed where the DA could not keep aircraft on their nominal route. These situations included the following. First, there were times when two arrivals would essentially be tied at the metering fix and speed control involving both aircraft could not provide adequate separation. Second, arrivals from the North became known to the controller much later than Western arrivals. Finally, the DA version tested did not make conflict checks at the intermediate waypoint (Hayden). Since this point occurred prior to any DA speed control taking effect, there was a potential conflict at earlier fixes prior to metering fix arrival which the controllers needed to resolve. It is clear that even though some vectoring was necessary, controllers agreed that it was easy to combine the DA generated advisories and their own vectoring or speed commands.

\section{Training}

Since the automation aid had not been evaluated before in an interactive workstation environment, an estimate was made that one day of training would be sufficient. Based on questionnaire responses and on observations made during the course of the evaluation, it was clear that a more carefully conceived training plan is required, and more than one day needs to be allotted for training. The main interactive tool was the mouse, but many subjects were not familiar with the use of the mouse. For those unfamiliar with the mouse, the training was too short. Controllers commented on their unfamiliarity with the mouse, and their preference for the trackball currently in use in the ATC system. Two specific shortcomings in the use of the automation aids were also evident from the questionnaires: First, a few controllers were not clear on what the SEP2 function was and how it differs from SEP1. Second, 50\% of the controllers agreed that the vertical time line provided useful sequence and schedule information and that they indeed used it in their evaluation runs. Others disagreed, with one controller specifically commenting that the time line was "just not used, ... use unclear to me."

\section{Simulation Realism}

Controllers stated that the simulation display was generally realistic and that voice communications with the 727 simulator pilot and the pseudopilot were good. However, they did comment on some features that are available in the current system, but which were not available in the simulation. The major criticisms were that the simulation could not deconflict overlapping tags, and that target history information was not provided. Also, there were some concerns expressed on the uniformity of aircraft models. One specific example of this is that all aircraft had the same descent rate, rather than a range of descents encountered with actual traffic. (This artifice results from the limited number of aircraft that were modeled in the DA.) One controller commented that it was essential to include overflights in future simulations, since they do strongly affect the handling of arrival traffic and contribute to controller workload.

\section{Use of the Interactive Graphics Display}

Controllers strongly supported the use of color. They particularly commented on how color helped them sort out classes of information more readily. The feature of highlighting an aircraft under specific consideration (i.e., when the color of the aircraft and its tag changes from green to yellow) was singled out as being particularly useful. Use of the mouse, on the other hand, received mixed reviews with about half the controllers favoring its use. Again this relates to the prior familiarity of the controller with mouse operation and the training on its use. Also, a lack of speed in the computer response may have been responsible for some of the unfavorable reaction. $A$ much faster workstation is currently in use. 


\section{Concluding Remarks}

The Descent Advisor (DA), an automation toolbox which provides advisories and suggested clearances to achieve desired time or distance spacing, was evaluated in a real time simulation at NASA Ames. Controller evaluations indicated that the aid can be integrated effectively in today's environment. One member of the arrival-sector controller team utilized clearances generated by the DA, while the second used manual flight strips as per current practice. When problems existed which fell outside the domain of the aid, controllers used conventional vectoring techniques to establish the desired spacing and then resumed using the DA without any difficulty. Controllers used the aid in various ways, some relying heavily on the time line data while others concentrated on the auxiliary information provided directly on the map. Thus, even in this initial evaluation, the operation was sufficiently flexible so that controllers did not feel that the tool restricted their freedom.

A major issue confronting the continued development of the DA as well as other automation aid development is the need for adequate training so that controller evaluations are meaningful. The DA as evaluated is not a simple tool nor are the controllers accustomed to the sophisticated display format in which it was presented. Adequate time should be allowed for subject training and a step-bystep training strategy needs to be developed. In addition, it was found that the technique of working with a group of controllers for a considerable period of time so that these controllers would then train the controller subjects was effective.

The plan for continued development includes incorporating specific controller suggestions in the simulation and conducting several additional ATC simulations at Ames to optimize the effectiveness of the DA in an operational environment. This will be followed by an evaluation at a major traffic center.

\section{References}

${ }^{1}$ Erzberger, H. and Nedell, W.: Design of Automated System for Management of Arrival Traffic, NASA TM-102201, 1989.

${ }^{2}$ Davis, T. and Green, S.: Piloted Simulation of a Ground-Based Time Control Concept for Air Traffic Control, NASA TM-101086, 1989.

${ }^{3}$ Foss, F. and Hinkleman, J.W.: Denver ARTCC Evaluation of PROFS Mesoscale Weather Products, Joint Report-U.S. Depts. of Commerce and Transportation, Jan. 1984.

${ }^{4}$ DeLoach, R. and Houck, J.A.: Pilot Evaluation of Population-Minimal Ground Tracks in the Airport Community, J. Aircraft, Vol. 24, No. 9, Sep. 1987, p. 603.

${ }^{5}$ Green, S., Davis, T. and Erzberger, H.: A Piloted Simulator Evaluation of a Ground-Based 4D Descent Advisor Algorithm, AIAA-87-2522-CP, Guidance, Navigation, and Control Conference, Monterey, CA, Aug. 1987.

6Tobias, L.: Automated Aircraft Scheduling Methods in the Near Terminal Area, J. Aircraft, Vol. 9, No. 8, Aug. 1972, p. 520.

${ }^{7}$ Tobias, L. and Scoggins, J.: Time-Based Air Traffic Management Using Expert Systems, IEEE Control Systems Magazine, Vol. 7, No. 2, Apr. 1987, p. 23.

${ }^{8}$ Volckers, U.: Computer Assisted Arrival Sequencing and Scheduling with the COMPAS System. Conference Proceedings, Efficient Conduct of Individual Flights and Air Traffic, AGARD, No. 410, June 1986, p. 54-1. 


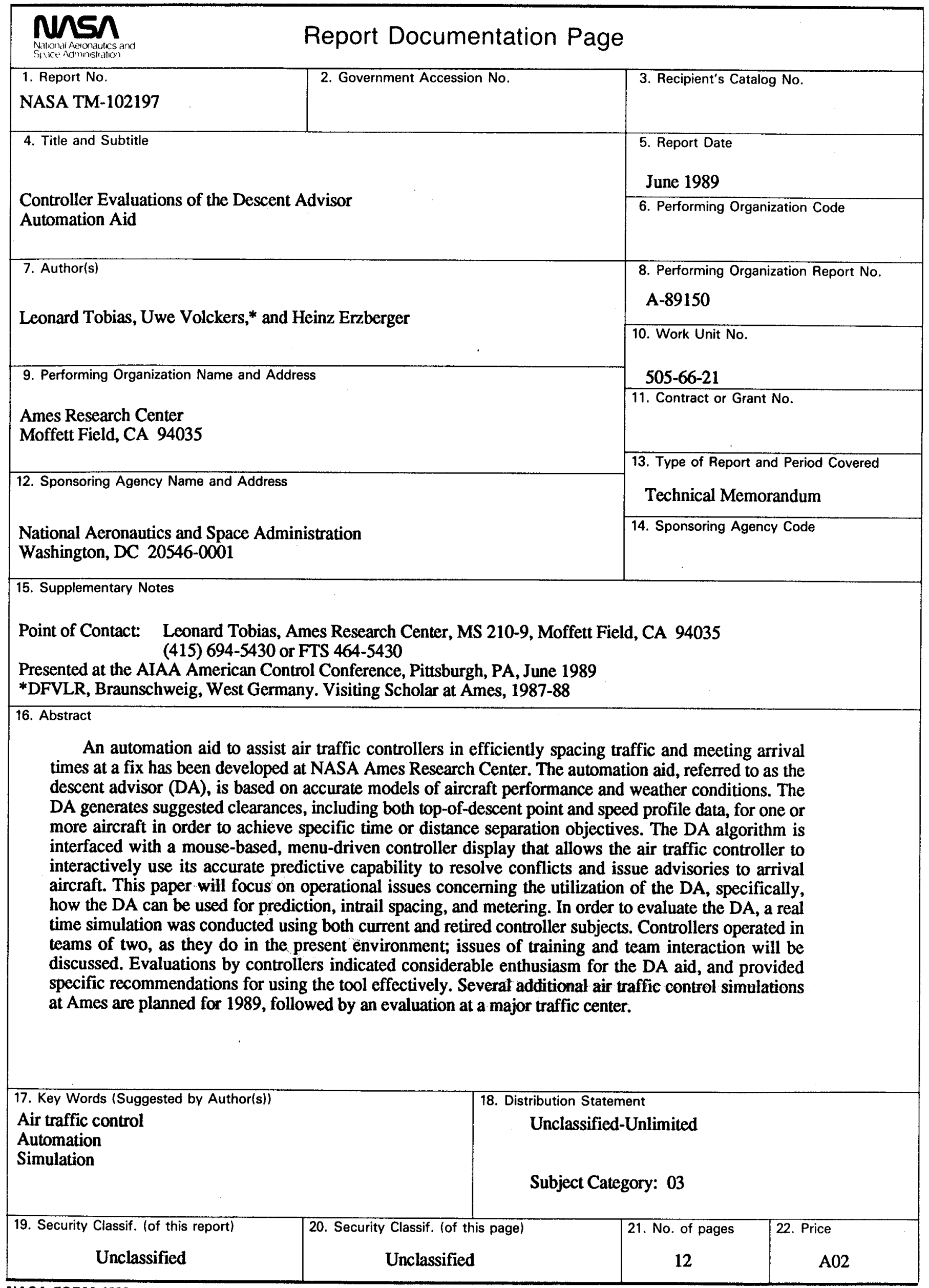


